See discussions, stats, and author profiles for this publication at: https://www.researchgate.net/publication/323911331

\title{
What makes a good placement? Findings of a social work student-to-student research study
}

Article in Social Work Education · March 2018

DOI: 10.1080/02615479.2018.1450373

\section{CITATIONS}

2

2 authors:

Niamh Flanagan

Maynooth University, Ireland

15 PUBlications 10 Citations

SEE PROFILE
(2) University College Dublin

12 PUBlications 3 CitATIONS

SEE PROFILE

Some of the authors of this publication are also working on these related projects:

Project $\quad$ Promoting social work practitioner research View project

Project Information Behaviour of Social Workers View project 


\title{
What makes a good placement? Findings of a Social Work Student-to-Student Peer Research Study
}

Dr Niamh Flanagan and Dr Elaine Wilson

Niamh Flanagan is a lecturer in the Social Policy, in the Department of Applied Social Studies, Maynooth University. Her research interests include social work research and education, in particular the role of educational technology, information behaviour and the evidence-base of policy and practice.

Elaine Wilson is an Assistant Professor in the School of Social Policy, Social Work and Social Justice, University College Dublin where she is also Director of Professional Practice. Her research interests include social work education and adult learning as well as the psychosocial needs of people with cancer and the social construction of illness. .

Correspondence to Dr Elaine Wilson, School of Social Policy, Social Work and Social Justice, Hanna Sheehy-Skeffington Building, University College Dublin, Belfield, Dublin 4, Ireland.

E-mail: elaine.wilson@ucd.ie

\begin{abstract}
Social work fieldwork placements are recognised as a key component of social work education. This article analyses the experiences of students who have completed one social
\end{abstract}


work placement and examines what they felt was most effective in aiding their learning. The innovative methodology used for the research enabled first year students to design an on-line survey which they administered to their second year student colleagues. As a result the first year students gained experience in designing and administering a piece of research, but also gained a greater understanding of what previous students have found assisted their learning on placement. This cross-sectional research surveyed accessed the 2014/15 cohort of year 1 and year 2 Masters in Social Work (MSW) students. It was conducted in two phases: in the first phase a year 1 student-staff team surveyed year 2 students who had just completed their placements, and in the second phase staff researchers surveyed both year 1 and year 2 students who had just completed their placements.

Students reported how prepared they felt for placement and also who or what facilitated their learning on placement. Students' perception of the volume of learning on placement was strongly correlated with satisfaction. It is argued that being able to clearly identify types of interaction that enhance students' learning, leads to more positive outcomes for all involved in the placement experience.

\section{Keywords:}

Social work, practice placement, practicum, practice learning, student experiences

\section{Introduction}

Fieldwork placements, also known as practicum or internships, are acknowledged to be central to social work education (Maidment, 2000), viewed as the 'sacred cow' (Gursansky \& Le Sueur, 2012) or 'signature pedagogy' of the social work profession (Council of Social Work Education, 2008). It has been described as 'the component of social work education 
where students learn to practice social work through delivering social work services in agency and community settings' (Bogo, 2006). The practicum offers students the opportunity to learn by 'doing' (Chui, 2009) and apply the theoretical foundations of the profession to practice, resulting in 'a more profound and lasting impact than classroom teaching' (Domakin, 2014).

In the UK, Ireland, Australasia and North America placements are a required and integral component of the social work education curriculum. They are usually organised by the universities, in partnership with statutory, voluntary and community social work agencies. In Ireland a typical unit of practice placement comprises the student and practice teacher, with a practice tutor acting as the liaison between the university, student and practice teacher. As group supervision in fieldwork placements are uncommon, the exclusive nature of the practice teacher, tutor and student relationship means that students from the same qualifying class can have different learning experiences on placement. Teasing out what contributes to the success of placements and maximises learning, represents a key opportunity to further enhance learning for all members of the placement practice team. Students' perceptions in particular offer a first-hand, person-centred, experiential insight into what facilitates their learning on placement.

\section{Literature Review}

The learning that students achieve on placement has a direct impact on their future functioning as professional social workers, and so it is essential that the learning environment is a positive one where students can gain as much as possible. Practice placements, make a huge difference to the quality of social programs and well-being in society (Bogo, 2015). 
Bogo contends that the 'link between social work education and field education, effective clinical social workers and social programs, and wellbeing in society must be advanced' (2015, p. 322). Practice placements provide an essential link between university and practice learning (Boitel \& Fromm, 2014). They offer a crucial space where students are given the opportunity to integrate and contextualise their classroom learning. The responsibility for facilitating the field instruction learning process is largely devolved to agency personnel, described as practice teachers in Ireland and the UK.

Given the complexity of this form of learning, a sizable body of literature has developed on the range of techniques employed to support student learning during the practice placement learning (Abram et al, 2000; Ayala et al, 2012; Barron, 2007; Bogo, 2006; Chen \& Fortune, 2017; Chui, 2009; Domakin, 2014; Fortune et al, 2001; Giddings et al, 2003; Kanno \& Koeske, 2010; Knight, 1996; LaPorte \& Sweifach, 2011; Maidment, 2000; Parker, 2007; Wilson et al, 2009). It appears that a broad array of field instruction practices can support learning, with a tendency to move away from the apprenticeship model, where students gained knowledge by observing, and being observed by an experienced practitioner. Savaya et al (2003) described this shift towards a more complex arrangement of assessment and professionals learning in this field, in terms of articulated learning. Bogo and Globerman (1995, 1999) differentiate articulated learning in the context of teaching centre and field setting models. In the teaching centre model, the practice teacher is responsible for teaching both theory and practice, whereas in field setting learning a distinction is made between the theoretical knowledge being taught in the university and the practical knowledge acquired on placement. Current models tend to emphasise the importance of a more transparent processes that identifies classroom teaching with field experience. 
A wide range of pedagogical techniques used in practice teaching to support learning, include orientation, planned working, supervision, monitoring, guiding, feedback and assignments. Several approaches have been used to evaluate practice learning achievement and levels of student satisfaction with teachers and the practice learning environment (Domakin 2014; Kanno \& Koeste, 2010; Choy et al, 1998). Fortune et al (2001: 112) comment that "while the goal of social work education is competent performance in the role of professional social worker, students' perceptions of their placements are important as potential intermediate outcomes". However, in literature relatively little focus has been afforded to students' perceptions of what or who supports their learning.

Positive experiences and student satisfaction on placement tend to be associated with getting regular feedback on performance, feeling empowered as a learner with some autonomy, and being able to observe constructive role models (Bogo et al., 2004). Placement research does however highlight the multi-faceted nature of preparedness, encompassing confidence in some aspects of practice and less in others (Kamali et al, 2017), the value of curriculum training (Moylan \& Wood, 2017) and role of life experiences beyond the university curriculum in contributing to preparedness for social work placement (Inch, 2017).

Oliver et al (2017) foregrounds the issue of social work students' confidence to speak up and engage in difficult conversations about placements. The ability to advocate for oneself is an essential skill for students to learn, as advocating on behalf of clients or service users is fundamental to social work practice. The link between positive experiences and motivation to learn cannot be underestimated, and therefore supports the need to investigate what assists students learning on practice placement. 


\section{Methodology}

The study grew out of a staff-initiated, student-to-student dialogue project which formed part of an MSW programme in the Republic of Ireland. The study embraced an experiential learning approach where students were cast as both research-learners, as well as curriculumlearners, one that has been favoured in other settings (Earley, 2007; Rubin et al, 2010; Chilvers et al, 2012; McIntyre \& Paul, 2013; Wulf-Andersen et al, 2013). Joubert et al (2017) argue strongly in favour of engaging social work students in staff initiated research to support and foster research knowledge, competency and confidence. The approach aims to promote experience and competencies which are not easily accomplished in traditional classroom teaching. It is argued that combining experiential learning with support, facilitation and collaborative knowledge production holds much potential for development of research teaching. While the study aimed to initiate a dialogue between Year 1 and Year 2 MSW students to ascertain their experiences on placement, and to enable Year 1 students to develop their research skills, the substantive aim of the study was to analyse the quality of practice learning opportunities which social work students experienced on their fieldwork placements.

\section{Research Setting}

The social work programme requires students to undertake two practice placements of 14 weeks duration. Students are assessed using six domains and standards of proficiency as outlined by the state regulatory body. They are expected to integrate theory based learning acquired in the first semester with their practice placement experience. The assessment of students on placement is devolved to the practice teacher, who gathers evidence using a variety of means such as direct observation, co-working, reports from other colleagues and supervision. In terms of assessment social work placements in Ireland tend to have a mix of both the process and the competence models. The process model is based on premise that 
social work is a nuanced blend of values, knowledge and skills and that each student is required to have the capacity to cope with an infinite variety of situations that arise in practice, many of which may not be anticipated. There is a particular focus on the student's ability to apply relevant knowledge and skills and follow accepted procedures to develop effective relationships and achieve practice goals. This approach however, leads to questions about the level of rigour in the assessment process, and how student's progress is measured. The competence model is more outcome-oriented with clear and overt assessment criteria. Whilst it provides a more transparent process for assessment, the concern with this approach is that it may not capture the nuanced world of social work in practice. Both practice teacher and student write a detailed, evidence-based placement report to demonstrate the student's learning. A minimum of two pieces of evidence is required in each of six domains that are prescribed by a social work regulatory board and the practice teacher is expected to justify a pass/fail recommendation in a report. All recommendations are then assessed under the University's exam process.

\section{Study Design \& Sample}

On completion of their practice placements, a cohort of MSW students were invited to participate in this descriptive study. The study, which employed a cross-sectional design, took place in two phases: one in which a Year 1 student-staff research team surveyed a convenience sample of Year 2 students (2014), and a subsequent phase (2015) when staff researchers surveyed both student groups $(\mathrm{N}=95)$. As such Year 2 students were invited to participate twice, after each of their practice placements. The final sample of 100 responses represents a 90\% response rate from Year 1 students and 60\% from Year 2.

\section{Ethical Review}

Ethical approval for the study was awarded by the University Human Research Ethics Committee. 


\section{Reviewing Literature}

Building on a preliminary literature review conducted by the authors, students reviewed selected literature, using blogs and in-class discussion forums to expand their understanding of the complexities of practice learning processes. This lead to the key themes being explored.

\section{E-survey Instrument}

In collaboration with the authors, Year 1 students designed and administered an e-survey of students' learning experiences on placement. Themes, identified in student reviews of literature, were assigned to teams of students who developed open and closed questions for each. These included: perceived satisfaction and success of the placement, preparation and perceptions of preparedness for placement; the identification of people who were instrumental in the success of placements; and tools which facilitated learning on placement. One student team was assigned responsibility for coordination of questions and another team was assigned responsibility for development of ethically sound recruitment documentation.

The Phase 1 survey was administered via an online survey tool yielding a $77 \%(n=37)$ response rate from Year 2 students. Basic frequency tables were returned to teams to enable them to analyse assigned themes. Data from the students' survey, which comprised Phase 1 of the study, was written up in a Wikispaces Classroom, an online social writing platform for education, and subsequently redrafted into a conference poster. Because the study was originally designed as a student-to-student dialogue project, with Year 2 sharing their experiences with Year 1 peers, many of the open response comments are framed as advice. The study combined data from Phase $1(n=37)$ with data from a second staff-run phase of the study. Minor amendments were made to the questionnaire and recruitment documentation and it was administered to Year 1 and Year 2 students after their 2015 placement. Phase 2 
achieved a $66 \%$ response rate $(n=63)$ resulting in an overall response rate of $70 \%(n=100)$ across the two phases. Univariate and bivariate analysis of the combined database was undertaken by the authors using IBM SPSS Statistics version 20.

\section{Limitations}

A methodological limitation of this study was its cross-sectional design and the study would have undoubtedly benefited from a longitudinal element which would have facilitated pre and post questioning as opposed to retrospective questioning. . Correlation with academic results and triangulation with responses from other members of the placement learning team would have increased the validity of data. However it would also have undoubtedly have had an impact on ethical considerations and response rates. A further methodological limitation was the single-school convenience sample used in this study which may not fully represent practice learning in the profession as a whole.

\section{Findings}

Key themes that emerged were:

1. Overall satisfaction with the placement experience

2. How prepared students felt for placement

3. Who and/or what facilitated students learning on placement

\section{Satisfaction}

Half of students were very satisfied and a further $40 \%$ satisfied with their social work practice placement (Table 1). 


\begin{tabular}{lcr}
\hline Table 1: Students' overall satisfaction with practice placement \\
\hline & $n$ & $\%$ \\
\hline Very satisfied & 50 & $50 \%$ \\
Satisfied & 40 & $40 \%$ \\
Neither satisfied nor dissatisfied & 2 & $2 \%$ \\
Dissatisfied & 6 & $6 \%$ \\
Very dissatisfied & 2 & $2 \%$ \\
\hline Total & 100 & $100 \%$ \\
\hline
\end{tabular}

$M d=1.5$

\section{Amount of Learning on Placement}

The majority of students indicated that they 'learnt a lot' on placement with a further third reporting that they 'learnt more than expected' (Table 2).

Table 2: Students' perception of overall amount of practice learning acquired on placement

\begin{tabular}{lcc}
\hline & $n$ & $\%$ \\
\hline Much more than expected & 36 & $36 \%$ \\
Learnt a lot & 47 & $48 \%$ \\
Some learning & 16 & $16 \%$ \\
No learning & 0 & $0 \%$ \\
\hline Total & 99 & $100 \%$ \\
\hline Md=2 & \multicolumn{2}{c}{ No answer 1 }
\end{tabular}

Placement success, in terms of satisfaction and learning, were strongly correlated with each other $\left(\mathrm{r}_{\mathrm{s}}=.62, \mathrm{P} \leq .001\right)$ indicating that personal learning played a significant part in determining satisfaction with placements. 
The level of students' confidence before placement was assessed retrospectively. The median confidence in preparedness was 'neither prepared nor unprepared' and just under half of the students reported that they felt, at least somewhat, prepared for their placement (Table 3). Of concern, however, is the finding that over a quarter felt unprepared.

\begin{tabular}{lcr}
\hline \multicolumn{2}{c}{ Table 3: Students ' retrospective perception of their level of preparedness for } \\
& $n$ & $\%$ \\
\hline & 3 & $3 \%$ \\
\hline Fully prepared & 45 & $45 \%$ \\
Somewhat prepared & 24 & $24 \%$ \\
Neither prepared nor unprepared & 23 & $23 \%$ \\
Somewhat unprepared & 5 & $5 \%$ \\
Totally unprepared & 100 & $100 \%$ \\
\hline Total & & \\
\hline
\end{tabular}

$M d=3$

Confidence did not have a significant impact on overall satisfaction. However pre-placement confidence did impact on the amount of learning, with those feeling 'fully prepared' and those feeling least prepared reporting the most learning $\left(\mathrm{r}_{\mathrm{s}}=.30, \mathrm{P} \leq .05\right)$. Those who were more confident but ultimately less prepared were less satisfied $(\bar{x}=1.9)$ than those who accurately estimated their preparedness for placement $(\bar{x}=1.7)$ or those who underestimated their preparedness $(\overline{\mathrm{x}}=1.6)$. However these differences were not statistically significant.

\section{Preparedness for placement}

Students were also asked to rate how prepared they actually were for their placement. Responses indicated that, overall, the student body had underestimated its preparedness for 
placement $(\mathrm{Z}=-1.961, \mathrm{P} \leq .05)$ with the median rating shifting upward to 'somewhat prepared' (Table 4). Moreover, the proportions reporting being unprepared for placement fell by $10 \%$.

\begin{tabular}{lcr}
\hline \multicolumn{4}{c}{ Table 4: Students' retrospective assessment of their actual level of } \\
preparedness for placement
\end{tabular}

Comparing pre-placement confidence with actual preparedness, most students did not change their perception of how prepared they were for placement (Table 5). A quarter realised that they were more prepared than anticipated and just over one-in-ten felt that they were less prepared than anticipated.

\begin{tabular}{lcr}
\hline \multicolumn{2}{c}{ Table 5: Comparison of students' confidence and level of preparedness for } \\
placement
\end{tabular}


While, as indicated above, pre-placement confidence did impact on the the level of learning, actual preparedness did not have a significant impact on learning or satisfaction. In fact those who were least prepared tended to report most learning. Elaboration on the specific issues which contributed to a sense of not being prepared for placement $(n=20)$ focused on procedural issues such as needing more assessment skills $(n=5)$, familiarity with procedures and protocols $(n=5)$ or knowledge about the placement setting, agency and its clientele $(n=5)$. However, one student advised:

I don't think it is possible to prepare everyone as the placements are all so different. It's important to relax and accept that you will learn as you go.

It was difficult to draw inferences about preparedness for the many social work settings because these were diverse and variable in terms of setting and client group. However, it was noteworthy that students placed in child and family and adoption and fostering settings more accurately predicted their level of preparedness than students in other placements who tended to underestimate their preparedness.

\section{How did students prepare for placement?}

Most students $(\mathrm{n}=90)$ undertook some preparation for placement. In all cases this involved reading or researching, most commonly finding out about the agency and its practices $(n=44)$, reading policies, procedures and legislation $(n=29)$, reviewing theories and methods $(n=22)$, undertaking recommended reading $(\mathrm{n}=16)$, and reviewing lecture notes $(\mathrm{n}=16)$.

Engaging in more than one preparatory task appeared to contribute to preparedness although this was not statistically significant. Some supplemented reading by asking others about their experiences of placement or settings $(n=14)$. Others engaged in induction $(n=5)$, preplacement meetings $(n=5)$, or bought suitable attire $(n=4)$. Reading and enquiring in 
preparation for placement did not have a significant effect on pre-placement confidence, satisfaction or learning on placement. However, reading about the agency did contribute to confidence $(\mathrm{u}=819.5, \mathrm{P} \leq .01)$, although not to preparedness.

\section{Who facilitated students' learning?}

Practice teachers and agency staff represented the mainstay of support for students' learning, providing help that facilitated learning on a daily $(n=60,64 \%)$ or weekly basis (teacher $n=28$, $30 \%$, Agency $\mathrm{n}=19,20 \%$ ). Supports from practice tutors were less frequent, usually monthly or less, and from the permanent university staff, typically less than monthly.

\section{Practice Teachers}

Nearly two thirds of students rated their practice teacher as 'very helpful' in facilitating their learning on placement, and a further quarter rated their teacher as 'helpful' (Table 6). A small number of students reported that their teacher was unhelpful or very unhelpful.

\begin{tabular}{lrr}
\hline \multicolumn{3}{c}{$\begin{array}{c}\text { Table 6: Helpfulness of Practice Teachers in facilitating } \\
\text { learning on placement }\end{array}$} \\
\hline Very helpful & $n$ & $\%$ \\
Helpful & 62 & $64 \%$ \\
Neither helpful nor unhelpful & 22 & $23 \%$ \\
Unhelpful & 4 & $4 \%$ \\
Very unhelpful & 4 & $4 \%$ \\
\hline Total & 5 & $5 \%$ \\
\hline
\end{tabular}

Md=1 No answer 3


Underlining the central role of practice teachers in practicum, ratings of their helpfulness were positively correlated with both overall satisfaction $\left(\mathrm{r}_{\mathrm{s}}=.52, \mathrm{P} \leq .001\right)$ and learning on placement $\left(\mathrm{r}_{\mathrm{s}}=.43, \mathrm{P} \leq .001\right)$. The frequency with which teachers provided support also impacted upon satisfaction $\left(\mathrm{r}_{\mathrm{s}}=.43, \mathrm{P} \leq .001\right)$ and learning $\left(\mathrm{r}_{\mathrm{s}}=.48, \mathrm{P} \leq .001\right)$ suggesting that the more support a practice teacher offered, the more the students gained from the placement. Moreover, the frequency of support from practice teachers was negatively correlated with confidence $\left(\mathrm{r}_{\mathrm{s}}=-.36, \mathrm{P} \leq .001\right)$ and preparedness $\left(\mathrm{r}_{\mathrm{s}}=-.25, \mathrm{P} \leq .05\right)$ suggesting that those who felt less confident and were least prepared received more frequent support.

The central role of practice teachers in the success of placements was acknowledged in ratings and comments. However, the corollary of this, that poor practice teachers can undermine a placement experience, was also noted. Concerns about this, and the power attributed to such teachers, were expressed by a number of respondents. The frequency and availability of many teacher-led learning tools such as formal and informal supervision, induction and feedback all appeared to impact on ratings of satisfaction with practice teachers $(\mathrm{P} \leq .05)$. Assistance with the management of caseloads had one of the strongest impacts on practice teacher ratings $\left(\mathrm{r}_{\mathrm{s}}=-.53, \mathrm{P} \leq .001\right)$.

Most practice teachers were considered very helpful $(n=40,45 \%)$ or helpful $(n=29,33 \%)$ in guiding students' navigation of the link between theory and practice.

In some cases I would express to him that I did not believe I was using enough theory in my practice. In response, we would do through how the case was going and some of the discussions I was having with clients and he would highlight examples of theories that I had been, unknowingly, applying. 
Guidance on theory use contributed most strongly to ratings of practice teachers $\left(\mathrm{r}_{\mathrm{s}}=.63, \mathrm{P} \leq\right.$ $.001)$, overall satisfaction with placement $\left(\mathrm{r}_{\mathrm{s}}=.63, \mathrm{P} \leq .001\right)$ and levels of learning on placement $\left(\mathrm{r}_{\mathrm{s}}=.50, \mathrm{P} \leq .001\right)$. Factors contributing to less positive experiences included a small number $(n=4)$ who expressed concern that practice teachers knowledge of theories, as one respondent put it, was 'a little rusty'.

\section{Agencies}

Agencies were rated as helpful or very helpful in facilitating learning on placement by $85 \%$ of students (Table 7). Again, this was significantly correlated with satisfaction $\left(\mathrm{r}_{\mathrm{s}}=.56, \mathrm{P} \leq\right.$ $.001)$ and learning on placement $\left(\mathrm{r}_{\mathrm{s}}=.38, \mathrm{P} \leq .001\right)$.

\begin{tabular}{|c|c|c|}
\hline \multicolumn{3}{|c|}{$\begin{array}{c}\text { Table 7: Helpfulness of Agencies in facilitating learning on } \\
\text { placement }\end{array}$} \\
\hline & $n$ & $\%$ \\
\hline Very helpful & 52 & $54 \%$ \\
\hline Helpful & 30 & $31 \%$ \\
\hline Neither helpful nor unhelpful & 9 & $9 \%$ \\
\hline Unhelpful & 3 & $3 \%$ \\
\hline Very unhelpful & 2 & $2 \%$ \\
\hline Total & 96 & $99 \%+$ \\
\hline $\begin{array}{l}M d=1 \\
+ \text { deviation from } 100 \% \text { due to }\end{array}$ & & swer 4 \\
\hline
\end{tabular}

A high intercorrelation between the helpfulness of practice teachers and agency helpfulness makes it difficult to differentiate between the two $\left(\mathrm{r}_{\mathrm{s}}=.53, \mathrm{P} \leq .001\right)$. However, non-parametric partial correlations show significant correlations, indicating that the contribution of agencies 
to satisfaction with placement $\left(\mathrm{r}_{\mathrm{s}}=.39, \mathrm{P} \leq .001\right)$ and overall learning $\left(\mathrm{r}_{\mathrm{s}}=.21, \mathrm{P} \leq .05\right)$, although weaker, was independent of practice teachers.

\section{Practice Tutors}

Support from practice tutors was significantly less frequently than support from practice teachers $(Z=-7.902, P \leq .001)$, or agencies $(Z=-8.317, P \leq .001)$. It is therefore not surprising that practice tutors received lower average ratings (Table 8).

\begin{tabular}{lcr}
\hline \multicolumn{2}{c}{ Table 8: Helpfulness of Practice Tutors in facilitating learning on placement } \\
\hline & $n$ & $\%$ \\
\hline Very helpful & 28 & $29 \%$ \\
Helpful & 35 & $36 \%$ \\
Neither helpful nor unhelpful & 22 & $23 \%$ \\
Unhelpful & 7 & $7 \%$ \\
Very unhelpful & 5 & $5 \%$ \\
\hline Total & 97 & $100 \%$ \\
\hline Md=2 & & No answer 3
\end{tabular}

The helpfulness of practice tutors did not impact on, or detract from overall satisfaction or learning on placement. However, helpfulness of tutors did impact, albeit moderately, on preparedness for placement $\left(\mathrm{r}_{\mathrm{s}}=.22, \mathrm{P} \leq .05\right)$. Moreover, greater frequency of support from practice tutors was associated with greater levels of preparedness $\left(\mathrm{r}_{\mathrm{s}}=.33, \mathrm{P} \leq .001\right)$. Of course engagement with practice tutors during placement isn't always necessary. Indeed only 21 respondents reported issues arising that required the assistance of practice tutors. These issues included discussion of a challenging case, inadequate supervision, poor student-teacher relationships, caseload management, and work familiarisation. 
Hesitation at involving the practice tutor was expressed by a few respondents for fear it would undermine the student-teacher relationship.

Despite having access to a good practice tutor who could argue on my behalf, and some issues were presented, I felt like I could not rock the boat too much while on placement

In some cases $(n=5)$ the need for further university support arose from a lack of clarity about, or confidence in, the practice tutor's role. Regrettably, but understandably, requiring the support of the tutor was negatively associated with overall placement satisfaction $(\mathrm{u}=546.5$, $\mathrm{P} \leq .05)$ and learning $(\mathrm{u}=481.5, \mathrm{P} \leq .01)$.

\section{The University}

On average supports were received from the University less than monthly, significantly less frequently than from teachers, agencies or tutors $(\mathrm{P} \leq .001)$. This support was rated as very/helpful by $44 \%(n=43)$, 'neither helpful nor unhelpful' by a sizable proportion of respondents $(n=42,43 \%)$, and very/unhelpful by $12 \%(n=12)$.

As with practice tutors, neither the helpfulness of the University nor the frequency of this support impacted on overall satisfaction or learning on placement.

I did not feel like I could turn to my tutor or to the college about any of the difficulties that I was facing as I was aware that they would talk to my Practice Teacher about it and I felt that would make things worse with her. I think that had I had the opportunity to tell my tutor or the college in confidence just to avail of advice, this would have made my experience wholly easier. 
The helpfulness of the University did, however, have an impact on pre-placement confidence $\left(\mathrm{r}_{\mathrm{s}}=.26, \mathrm{P} \leq .05\right)$ and preparedness $\left(\mathrm{r}_{\mathrm{s}}=.41, \mathrm{P} \leq .001\right)$. Questioned on the value of a number of University supports, respondents most commonly rated each on the midpoint of the scale. The value of support on the mid-placement recall day, advice on how to deal with workplace stress, conflict and safety and access to placement reports of former students were each rated on average as 'neither useful nor not useful'. While these did not achieve high value ratings, neither did the value expressed correlate with satisfaction with placement or learning on placement.

A number of suggestions were made about how to improve such support, particularly given the diverse nature of placement settings. These included: the provision of setting specific preparation time $(\mathrm{n}=12)$, more opportunities to talk with students who had experience of the placement setting $(n=9)$, and the opportunity to review placement reports $(n=8)$. Suggestions for greater skills preparation with regard to a wide range of areas (>23) were cited, most common among these were assessments $(n=9)$, workplace stress, conflict and safety $(n=5)$, child protection issues $(n=4)$ and writing skills $(n=6)$. Nearly a fifth of students indicated that they would have benefited from greater contact with the University during placement.

[would benefit from] more [college] involvement during placement, it's a long time until call back day and if you're struggling or having any issues, it could almost be too late. Maybe an opportunity to link in more often as the only contact we ever had was regarding assignments. Contact with your tutor isn't as helpful as contact with the college would be.

As indicated earlier, the need for such support often arose because of a lack of clarity or confidence in the practice tutor role. Concern was sometimes expressed about this support where the placement was failing or failed, or where the student experienced a crisis. Some 
suggested regular check-ins or e-mail contact, while others noted the need for contact when there was a crisis.

Peer Support

It was scary going out on placement and the only other people who know and can appreciate what you're going through are your peers!!! Use and abuse the support!!!

Support from peers was rated highly by students with $82 \%$ indicating that they were helpful or very helpful while on placement (Table 9). However, help from peers was not positively correlated with overall satisfaction, learning or preparedness.

\begin{tabular}{lcr}
\hline \multicolumn{3}{c}{ Table 9: Helpfulness of Peers in facilitating learning on placement } \\
\hline & $n$ & $\%$ \\
\hline Very helpful & 37 & $39 \%$ \\
Helpful & 42 & $44 \%$ \\
Neither helpful nor unhelpful & 13 & $14 \%$ \\
Unhelpful & 3 & $3 \%$ \\
Very unhelpful & 1 & $1 \%$ \\
\hline Total & 94 & $101 \% \%$ \\
\hline Md=2 & & No answer 4 \\
+ deviation from 100\% due to rounding error & & \\
\end{tabular}

Peer support was surprisingly frequent given the diversity of geographical locations. Nearly three quarters of students $(n=69)$ reported receiving peer support that facilitated their learning weekly or more, and half of these daily. Most students employed multiple mediums for peer 
support, although the most commonly cited was social media $(\mathrm{n}=52)$ - including a class Facebook page.

[I got peer] support via social media (Whatsapp groups, facebook groups, individual social media contact), meeting up with members of the class outside placement for coffee to talk about placement and see how everyone is getting on, texts, calls, support from non-UCD students within placement was also great.

Students also received peer support by meeting face-to-face $(n=47)$, phone calls $(n=27)$ and texts/messaging $(n=19)$, meeting peers via work $(n=7)$, and some pointed to the value of having a peer on the same placement $(\mathrm{n}=17)$.

[There were] other students on my placement so I was lucky enough to have daily peer support.

A small group $(n=11)$ reported receiving peer support less than monthly. However, the group did not differ significantly from others in terms of support from other sources. Suggestions for further peer support included linking Year 1 students with Year 2 students who had completed similar placements $(n=6)$, structured group meetings/peer supervision $(n=4)$, and establishment of setting specific $(n=5)$ and geographic specific $(n=2)$ forums. Few specified mediums through which such groups could operate were mooted but suggestions included groups and confidential forums.

\section{Students lacking support}

Given the high interconnectedness between the helpfulness of teachers and agencies, and tutors and the University, it is worth looking more closely at those who generally reported low helpfulness ratings across the four stakeholder groups. Three students rated teachers, tutors, agencies and University staff as below helpful - one of these also rated peer support 
similarly. A further seven reported help from one of the agency, practice teacher, University staff or tutor. Although such small numbers make inferences unreliable this group were not significantly different from their peers with regard to confidence or preparedness but were significantly less satisfied with their placement $(\mathrm{u}=289, \mathrm{P} \leq .05)$ and rated their learning significantly lower $(\mathrm{u}=263.5, \mathrm{P} \leq .01)$.

\section{Additional Learning Supports}

Students learning was also supported in other ways, most notably through interpersonal communications. The most commonly cited support was from team members $(n=29)$.

The other workers in the office were extremely helpful and supportive ... I would definitely recommend getting to know the other professionals on placement because their roles taught me a lot and they happened to be a great source of support for me.

Support from team members included a broad range of interactions from informal conversation, through guidance, support and advice, provision of different perspectives, through formal talks. Peer support, discussed above, as well as support from other placement students facilitated learning $(\mathrm{n}=15)$, as did family and friends $(\mathrm{n}=10)$. Support derived from visits and contact with other agencies was noted by a handful of students $(n=7)$. The value of learning from clients and case files $(n=6)$ was noted, as was documentary sources $(n=10)$ such as libraries, internet, placement reports, policies, blogs and learning journals.

I found my reflective journal a great help as it helped me revise my practice but also 'switch off'.

In addition to strengthening of certain elements of practicum, for example by improved feedback, induction and supervision $(n=7)$, suggestions for additional supports were made by 
a third of respondents. These included supports such as a buddy system, a helpline, a colleague to talk to $(n=6)$, interaction with other services $(n=8)$, further training in suicide prevention, attachment theory, care and safety $(n=7)$, specific information on writing reports/plans, understanding ethical frameworks $(n=6)$, financial support $(n=3)$ and greater University support on crisis management $(n=3)$. The value of student integration into the team was raised by a handful of students $(n=4)$ who noted that policies of giving students different access and rights to staff created irritation and problems, while the opposite was a challenge for others.

"My practice teacher was of the opinion it's best to throw students (I was her first) in the 'deep end' by giving me a full case load (over 20 cases) on the basis that we are qualified in a few weeks. When I was struggling she told me that the whole department was busy and to get on with it."

Closing comments included suggestions to ameliorate the difficulties and stress associated with a fourteen-week placement, such as multiple shorter placements, or a longer interim break.

\section{Discussion}

The study's findings help provide some understanding of students' experiences of placement and ways in which systems of practice learning can be improved. The provision of high quality placements leading to strong student satisfaction is essential if we concur with Bogo's (2015) assertion that high quality practice placements lead to better qualified social work practitioners, and ultimately enhance wellbeing of society. Overall satisfaction with the placement experience and perceptions of learning were strongly correlated to student 
satisfaction with their practice teacher and placement agency. The study found that nearly $90 \%$ of the respondents were either satisfied with their practice teachers and agency.

Clear areas for improvement are also identified. It appears that students were somewhat unclear about the role of the practice tutor, and a number commented on their unwillingness to contact the tutor and 'rock the boat' on their placement, mirroring Oliver et al's (2017) concerns about student empowerment. The relatively negative responses about the support from the practice tutor may also reflect the fact that, significant involvement of a practice tutor during a placement occurs when there are problems or difficulties on placement. It is possible that a student is likely to be stressed if there are problems or difficulties, and so the placement as a whole is viewed in a more negative light.

While support of Practice Tutors and Universities was correlated with preparedness and preplacement confidence, of concern are the poor ratings that the University received in terms of support for students during placement. Students felt that they would benefit from greater involvement of this stakeholder group. One method of addressing this issue would be to combine the role of academic staff and practice tutor which, logically, would lead to a greater integration of the worlds of practice and academy. It may also lead students to feel more confident that the University are aware of their experiences on placement, and more empowered to consult it in times of difficulty. Lui et al (2013) go further when considering this issue and suggest that one of the ways to address the lack of involvement by universities in student placements would be to move away from the 'block' model, where academic learning and practice learning are carried out in separate blocks. Social work is a relatively new profession in China, having only been reintroduced to the university curriculum in the 1980s, and according to Lui et al (2013) they have the opportunity to learn from the experiences of other social work education programmes, specifically in the United States. 
They believe that an integrated model where practice learning and academic learning run concurrently would be preferable in the emerging Chinese context, allowing students to readily access both peer and academic support. Movement away from the block model has advantages, but one disadvantage is the lack of continuity for both students and clients in the practice learning setting. However it is addressed, it is clear that students' require greater input from the university while on placement.

Reflecting research on the value of peer support (Oliver et al, 2017), students gave and received significant support from peers. It would have been interesting to discover if students relied solely on the other students in their class, or whether there was interaction between the two years. One of the suggestions made by students was that they should receive more input from students who had been placed before in the agencies previously and could therefore share valuable experiences. Greater opportunities for information sharing and dialogue between the Year 1 and Year 2 students may also lead to an enhanced feeling of preparation for placement and support during placement. Although, as Oliver et al (2017) indicate, the difference between the years may put them outside the realm of peers.

In addition, it is important to try and understand what enables practice teachers to provide robust assessments of learning and systems of support for students. Fortune et al (2001) noted the importance of understanding what motivates students to learn, given that positive experiences can lead to increased desire and ability to learn. Thus a greater understanding of what practice teachers need to help their students would lead to more positive outcomes for students and positive learning environments. Savaya et al (2003) suggest that we should go even further and ensure a greater level of congruence between what is taught in the university and on placement, by establishing a formal framework to address the gap between academic and practice instruction. Further research could compare the experiences of students on 
placement in terms of what helped them to learn, with practice teachers' reflections on what they believed worked well or not so well.

\section{Conclusion}

This research used an innovative research design to examine what a cohort of MSW students believed helped them to learn on placement. The findings were relatively consistent with previous research, with regard to student satisfaction with their practice teacher being a strong correlate of overall satisfaction with their placement. Of interest was the relative dissatisfaction with university support during placement, and the importance of peer support. A re-evaluation of how the university currently supports students on placement is required to strengthen links with students. It is also clear that greater the congruence between university and practice learning leads to a more positive experience for student son social work practice placements. 


\section{References}

1st Year M.Soc.Sc. (Social Work) Students with Flanagan, N. \& Wilson, E. (2015) What facilitates learning on placement? unpublished poster presentation at: Irish Association of Social Workers Annual Conference, June 5 2015, Dublin, Ireland.

Bogo, M. (2015). 'Field education for clinical social work practice: Best practices and contemporary challenges'. Clinical Social Work Journal, 42(3), 317-324. doi:10.1007/S10615-015-0526-5

Bogo, M. (2006). 'Field instruction in social work: A review of the research literature', The Clinical Supervisor. 24(1-2), 163-193. doi: 10.1300/J001v24n01_09

Bogo, M. Regehr, C. Power, R. Hughes, J. Woodford, M. \& Regehr, G. (2004). 'Towards new approaches for evaluating student field performance: Tapping the implicit criteria used by experienced field instructors'. Journal of Social Work Education, 40(3), 417-426. Retrieved from https://doi.org/10.1080/10437797.2004.10672297

Boitel, C. \& Fromm, L. (2014). 'Defining signature pedagogy in social work education: Learning theory and the learning contract'. Journal of Social Work Education, 50(4), 608622. Retrieved from https://doi.org/10.1080/10437797.2014.947161

Chen. Q. \& Fortune, A.E. (2017). 'Student perceptions of the learning process during undergraduate field practicum: a qualitative study'. Social Work Education, 36(5), 467-480. doi: $\underline{10.1080 / 02615479.2016 .1224830}$

Chui, W. (2009). 'First Practice Placement', The Journal of Practice Teaching and Learning. 9(2), 10-32. doi: $10.1921 / 146066910 \times 518085$ 
Council on Social Work Education (2008). Educational policy and accreditation standards. [online]. Retrieved from at https://www.cswe.org/Accreditation/Standards-and-Policies/2008EPAS

Domakin, A. (2014). 'Are we making the most of learning from the practice placement?'. Social Work Education, 33(6), 718-730. doi:10.1080/02615479.2013.869315

Fortune, A. E. McCarthy, M. \& Abramson, J. S. (2001). 'Student learning processes in field education: Relationship of learning activities to quality of field instruction, satisfaction, and performance among MSW students'. Journal of Social Work Education, 37(1), 111-124. Retrieved from http://www.tandfonline.com/doi/ref/10.1080/10437797.2001.10779040

Giddings, M. Vodde, R. \& Cleveland, P. (2003). 'Examining student-field instructor problems in practicum: Beyond student satisfaction measures'. The Clinical Supervisor,

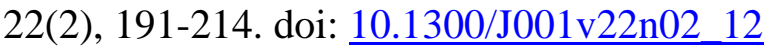

Gursansky, D. \& Le Sueur, E. (2012). 'Conceptualising field education in the twenty-first century: Contradictions, challenges and opportunities'. Social Work Education, 31(7), 914931. doi:10.1080/02615479.2011.595784

Inch, E. (2017). 'Are you ready? Qualifying social work students' perception of their preparedness to work competently with service users from sexual and gender minority communities'. Social Work Education, 36(5), 557-574. doi:10.1080/02615479.2016.1237628

Joubert, L., Hebel, L., McNeill, A., Firth, S., McFadden, E. and Hocking, A. (2017).

'Teaching research in social work through academic practitioner partnerships: Knowledge, competency and confidence'. Advances in Social Work and Welfare Education. 19(1), 37-48.

Retrieved from http://www.anzswwer.org/wp-

content/uploads/Advances_Vol19_No1_2017_Full_Document_v7_Final.pdf 
Kamali, A. Clary, P. \& Frye, J. (2017). 'Preparing BSW student for practicum: Reducing anxiety through bridge to practicum course'. Field Educator, 7(1). Retrieved from http://www2.simmons.edu/ssw/fe/i/16-133.pdf

Kanno, H. \& Koeske, G. F. (2010). 'MSW students' satisfaction with their field placements: The role of preparedness and supervision quality', Journal of Social Work Education. 46(1), 23-38. doi:10.5175/JSWE.2010.200800066

Knight, C. (1996). 'A study of MSW and BSW students' perceptions of their field instructors', Journal of Social Work Education. 32(3), 399-414. doi:10.1080/10437797.1996.10778470

Liu, M., Sun, F. \& Anderson, G. (2013). 'Challenges in social work field education in China: Lessons from the western experience'. Social Work Education. 32(2), 179-196. doi: $\underline{10.1080 / 02615479.2012 .723682}$

Maidment, J. (2000). 'Methods used to teach social work students in the field: a research report from New Zealand'. Social Work Education: The International Journal, 19(2), 145154. doi: $\underline{10.1080 / 02615470050003520}$

Marsh, P. \& Triseliotis, J. (1996). 'Ready to practice? Social workers and probation officers: Their training and their first year of work'. Avebury, Aldershot.

McIntyre, G. \&Paul, S. (2013). 'Teaching research in social work: Capacity and challenge', British Journal of Social Work. 43(1), 685-702.doi: $\underline{\text { 10.1093/bjsw/bcs010 }}$

Moylan, C.A. \& Wood, L. (2016). 'Sexual harassment in social work field placements: Prevalence and characteristics'. Affilia, 31(4), 405-417. doi:10.1177/0886109916644643 
Oliver, C., Jones, E., Rayner, A., Penner, J. \& Jamieson, A. (2017). 'Teaching social work students to speak up'. Social Work Education, 36(6), 702-714. doi: $10.1080 / 02615479.2017 .1305348$

Parker, J. (2007). 'Developing effective practice learning for tomorrow's social workers', Social Work Education. 26(8), 763-779. doi: 10.1080/02615470601140476

Rubin, D. Robinson, B. \& Valutis, S. (2010). 'Social work education and student research projects: A survey of program directors'. Journal of Social Work Education, 46(1), 39-55. doi: $\underline{10.5175 / J S W E .2010 .200800040}$

Savaya, R. Peleg-Oren, N. Strange, D. \& Geron, Y. (2003). 'Congruence of classroom and field instruction in social work: An empirical study'. Social Work Education, 22(3), 297308. doi: $\underline{10.1080 / 0261547032000083487}$

Wilson, G. O'Connor, E. Walsh, T. \& Kirby, M. (2009). 'Reflections on practice learning in Northern Ireland and the Republic of Ireland: Lessons from student experiences'. Social Work Education, 28(6), 631-645. doi:10.1080/02615470903027348

Wulf-Andersen, T. Morgensen, K. Hjort-Madsen, P. (2013). 'Researching with undergraduate students: Exploring the learning potentials of undergraduate students and researchers collaborating in knowledge production'. Journal of Research Practice, 9(2), Article M9. doi:10.1007/978-3-319-09716-9_14 